\title{
Different Risk Profiles of European Patients Using Direct Oral Anticoagulants or Vitamin K Antagonists: a Rapid Review
}

\author{
Katrin Krueger ${ }^{1} \cdot$ Kathrin Jobski $^{2}$ (D) $\cdot$ Annemarie Voss $^{3} \cdot$ Ulrike Haug $^{3,4}$ (D) \\ Accepted: 14 October 2020 / Published online: 14 November 2020 \\ (C) The Author(s) 2020
}

\begin{abstract}
Purpose of Review We investigated the risk profiles of patients using direct oral anticoagulants (DOAC) or vitamin $\mathrm{K}$ antagonists (VKA) in European cohort studies to estimate the importance of potential (measured or unmeasured) confounding factors in analyses comparing these drugs. We searched MEDLINE and EMBASE (2008-2018) for relevant studies and extracted information on age, sex, comorbidity, Charlson comorbidity index, HAS-BLED score (assessing risk of bleeding) and CHA2DS2VASc score (assessing risk of stroke).

Recent Findings Overall, 66 studies with 2,808,757 patients were included. Most patients were from France (37\%), Denmark (24\%) and Germany (23\%). In 56 studies (85\%), the focus was on patients with atrial fibrillation. Of the 43 studies comparing DOAC with VKA users, $33 \%$ reported a higher and $16 \%$ a lower age of DOAC compared with VKA users. The mean age varied by about 1 year in most of these studies. Rivaroxaban was used in the widest age range. Patients with DOAC more often had a history of stroke or bleedings, and patients with VKA more often had a history of diabetes, renal failure, cancer, heart failure or other heart diseases. Most studies did not observe differences regarding the HAS-BLED score or the CHA2DS2-VASc score between groups. Summary Our review suggests that there are relevant differences in the risk profiles of DOAC versus VKA users and between users of individual DOACs. Reported HAS-BLED or CHA2DS2-VASc scores did not reflect these differences. These patterns require careful consideration in the interpretation of observational studies comparing the effectiveness and the risks of these drugs, also when comparing the results of studies conducted in different countries.
\end{abstract}

Keywords Anticoagulants $\cdot$ Cohort studies $\cdot$ Patient characteristics $\cdot$ Risk profiles

This article is part of the Topical Collection on Pharmacoepidemiology

Supplementary Information The online version contains

supplementary material available at https://doi.org/10.1007/s40471-02000257-y.

Ulrike Haug

haug@leibniz-bips.de

1 Institute of Public Health, Charité Universitätsmedizin Berlin, Berlin, Germany

2 Department of Health Services Research, Faculty of Medicine and Health Sciences, Carl von Ossietzky University Oldenburg, Oldenburg, Germany

3 Department of Clinical Epidemiology, Leibniz Institute for Prevention Research and Epidemiologie - BIPS, Bremen, Germany

4 Faculty of Human and Health Sciences, University of Bremen, Bremen, Germany

\section{Introduction}

In the field of oral anticoagulants, several new substances have been approved over the past decade known as direct oral anticoagulants (DOAC), new oral anticoagulants or non-vitamin $\mathrm{K}$ antagonist oral anticoagulants (NOAC). Unlike vitamin $\mathrm{K}$ antagonists (VKA), they do not require routine monitoring for potential dose adjustments, as their pharmacokinetic properties are more predictable. The frequency of DOAC prescriptions has constantly increased in Europe [1••]. For instance, for nonvalvular atrial fibrillation (AF), the standardised rate of new DOAC users increased from 0.11 to 8.71 users per 10,000 people (2011-2015) for rivaroxaban and from 0.01 to 8.12 per 10,000 (2012-2015) for apixaban in six European countries (Denmark, France, Germany, Netherlands, Spain and UK) [1••]. In 2015, the rate of new DOAC users treated for AF ranged from nine (Spain) to 28 (Denmark) per 10,000 inhabitants $[1 \bullet \bullet$. Continuing increase is expected due to further extensions of approved indications. 
Following the stepwise approval of different DOAC, the comparison of their effectiveness and safety has been a matter of intense research. This includes observational studies, e.g. based on large healthcare databases where information to adequately control for confounding is often limited. Confounder control, however, is highly relevant as channelling bias and other reasons for selective prescribing could play an important role. Potential differences in the marketing strategies of the competing manufacturers between countries or differences in the health systems may lead to country-specific selection effects. Controlling for measured confounders is often not sufficient to overcome these sources of bias. For example, a recent database study - comparing the risk of bleeding, stroke and death of patients treated with different DOAC or VKAfound a higher mortality rate for rivaroxaban, but the authors argued that this effect may also be due to selective prescription of rivaroxaban for older patients [2 $\bullet$. To better assess the associated risk, adequate control of potential confounders such as "frailty" would be important, but this is typically challenging due to limited related information in large database studies.

If there are relevant differences in measured confounders between patient groups, it appears plausible that the possibility of unmeasured confounding also requires more attention in the interpretation of results. However, to date, the literature has not been systematically investigated regarding patient profiles of different DOAC users. To fill this gap, we performed a rapid review assessing and comparing the characteristics of patients treated with oral anticoagulants, in particular with DOAC, focusing on cohort studies conducted in Europe.

\section{Methods}

\section{Study Design}

A rapid review was conducted considering the recommendations for rapid reviews [3-6]. Additionally, the Cochrane Handbook of Systematic Reviews and the PRISMA (Preferred Reporting Items for Systematic reviews and Meta-Analysis) statement served as guidelines [7-9].

The bibliographic databases MEDLINE via PubMed and EMBASE via Ovid were systematically searched for studies published from January 1, 2008 - the year of the first approval of a DOAC within the European Union-until December 31, 2018. The search strategy was developed using the PICO scheme (population, intervention, comparison/study design, outcome) [7]. A search filter for cohort studies was used [10]. The detailed search strategy can be found in the appendix.

\section{Inclusion and Exclusion Criteria}

We included articles on studies
(A) Investigating patients with prophylaxis or therapy for thromboembolic diseases (i.e. prophylaxis of venous thromboembolism after hip and knee replacement, prophylaxis of stroke and systemic embolism in patients with atrial fibrillation, therapy and prophylaxis of deep vein thromboses and pulmonary embolism and prophylaxis of thrombotic events after acute coronary syndrome, which were approved indications for at least one DOAC within the European Union before 2018)

(B) Including patients treated with apixaban, dabigatran, edoxaban or rivaroxaban (i.e. studies only including patients treated with VKA were excluded)

(C) Which were cohort studies

(D) Which documented patient characteristics and outcomes with respect to the use, effectiveness and/or safety of the DOAC

(E) Including patients living in the European Union

Furthermore, for reasons of comprehension, only studies published in English, German or French were included (no resources for translation of studies were available). We also excluded studies published as abstract only.

\section{Selection Process}

As is customary for rapid reviews, the selection of studies was conducted by one person (KK) [5]. Duplicates were removed, and titles, abstracts and full texts were screened with respect to the inclusion and exclusion criteria [11]. The reasons for exclusion were documented.

The reporting quality of the included studies was described qualitatively with respect to the following domains: study design, research question, presence of a comparative group, potential selection bias or rather the relation of the number of included patients to the whole population, completeness of the searched patient characteristics and disclosure of conflicts of interest and funding.

One person (KK) extracted the characteristics of the studies and the patients. If documented, the HAS-BLED score used to assess the bleeding risk, CHA2DS2-VASc score predicting the risk of stroke and Charlson comorbidity index were considered. We only considered information on baseline characteristics before matching or weighting procedures.

\section{Results}

\section{Characteristics of Studies}

The search resulted in 2313 hits, 980 in MEDLINE and 1333 in EMBASE (Fig. 1). A total of 66 studies with 2,808,757 patients overall were included $[2 \bullet, 12 \bullet, 13 \bullet, 14 \bullet, 15 \bullet, 16 \bullet$, 17•, 18•, 19•, 20•, 21•, 22•, 23•, 24•, 25•, 26•, 27•, 28•, 29•, 


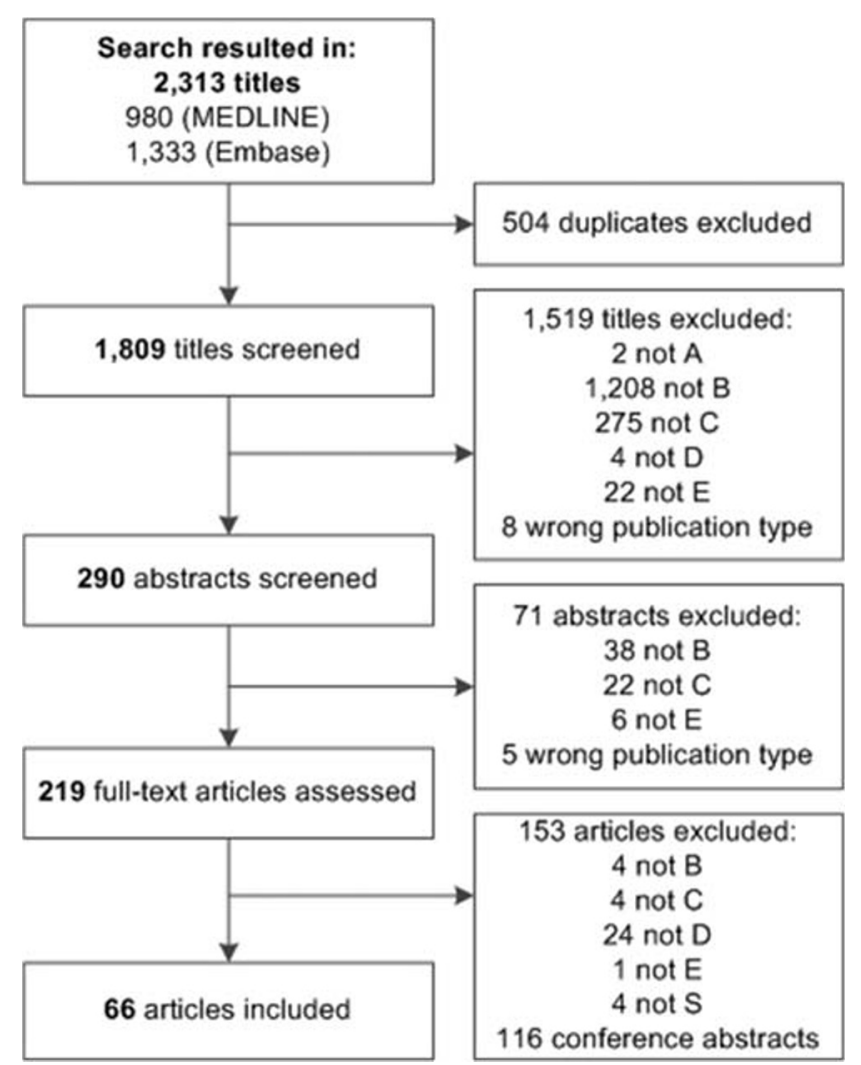

Fig. 1 Inclusion criteria: A = patients with thrombo-embolic diseases (approved for direct oral anticoagulants (DOAC) until 2018); B = therapy with DOAC; $\mathrm{C}=$ cohort study; $\mathrm{D}=$ patient characteristics; $\mathrm{E}=$ European patients; $\mathrm{S}=$ language English, German, French

$30 \bullet, 31 \bullet, 32 \bullet, 33 \bullet, 34 \bullet, 35 \bullet, 36 \bullet, 37 \bullet, 38 \bullet, 39 \bullet, 40 \bullet, 41 \bullet, 42 \bullet$, $43 \bullet, 44 \bullet, 45 \bullet, 46 \bullet, 47 \bullet, 48 \bullet, 49 \bullet, 50 \bullet, 51 \bullet, 52 \bullet, 53 \bullet, 54 \bullet, 55 \bullet$, $56 \bullet, 57 \bullet, 58 \bullet, 59 \bullet, 60 \bullet, 61 \bullet, 62 \bullet, 63 \bullet, 64 \bullet, 65 \bullet, 66 \bullet, 67 \bullet, 68 \bullet$, $69 \bullet, 70 \bullet, 71 \bullet, 72 \bullet, 73 \bullet, 74 \bullet, 75 \bullet, 76 \bullet$. A list of excluded full text articles can be found in the appendix.

Forty-seven of the $66(71 \%)$ included studies were published in 2017 or 2018 . There were 23 studies (35\%) from

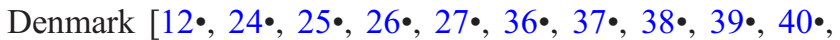
$41 \bullet, 42 \bullet, 44 \bullet, 52 \bullet, 53 \bullet, 61 \bullet, 62 \bullet, 63 \bullet, 66 \bullet, 67 \bullet, 68 \bullet, 69 \bullet, 70 \bullet]$,

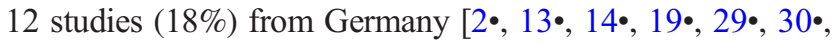
$31 \bullet, 34 \bullet, 43 \bullet, 50 \bullet, 71 \bullet, 76 \bullet$, 10 studies $(15 \%)$ from France $[15 \bullet, 16 \bullet, 18 \bullet, 20 \bullet, 21 \bullet, 32 \bullet, 47 \bullet, 48 \bullet, 49 \bullet, 60 \bullet$, four studies $(6 \%)$ from Italy $[57 \bullet, 73 \bullet, 74 \bullet, 75 \bullet]$ and four studies $(6 \%)$ from Sweden $[22 \bullet, 23 \bullet, 64 \bullet, 65 \bullet$. For the remaining countries, there were less than four studies each (Table 1). Three studies (5\%) included patients from more than one country $[17 \bullet, 45 \bullet, 56 \bullet]$. Most patients were from France $(n=1,040,557 ; 37 \%)$, Denmark $(n=667,008 ; 24 \%)$ and Germany $(n=643,665$; $23 \%)$.

The included 66 studies investigated the use, effectiveness and/or safety of the drugs. Three studies were reported as postauthorisation effectiveness and safety studies (PAES/PASS) with special methodical requirements of the regulatory authorities $\left[30^{\bullet}, 31^{\bullet}, 55^{\bullet}\right]$. The number of patients per study varied between 103 [33•] and 814,446 [32•]. Different data sources were used; some studies collected primary data, and others used routinely collected data from registries or the healthcare system (data not shown).

The majority of the studies $(n=56 ; 85 \%)$ included patients with atrial fibrillation treated with DOAC for stroke and systemic embolism prophylaxis $[2 \bullet, 12 \bullet, 13 \bullet, 14 \bullet, 15 \bullet, 16 \bullet, 17 \bullet$,

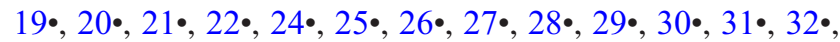

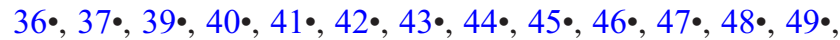

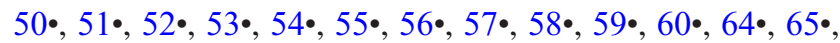
$67 \bullet, 68 \bullet, 69 \bullet, 70 \bullet, 71 \bullet, 72 \bullet, 73 \bullet, 74 \bullet, 75 \bullet, 76 \bullet$. Eleven studies $(17 \%)$ investigated patients with a DOAC prescription to treat or prevent deep vein thrombosis or pulmonary embolism [18•, $23 \bullet, 33 \bullet, 34 \bullet, 35 \bullet, 38 \bullet, 61 \bullet, 62 \bullet, 63 \bullet, 66 \bullet, 72 \bullet]$. One study (2\%) included patients treated for venous thromboembolism prophylaxis after hip or knee replacement [72•]. There was no study investigating prophylaxis in patients with acute coronary syndrome.

Sixteen studies (24\%) assessed direct oral anticoagulants $($ DOAC) without a comparator $[12 \bullet, 14 \bullet, 17 \bullet, 21 \bullet, 23 \bullet, 24 \bullet$, $29 \bullet, 33 \bullet, 34 \bullet, 43 \bullet, 46 \bullet, 49 \bullet, 51 \bullet, 54 \bullet, 55 \bullet, 73 \bullet$, and the others compared different DOAC with one another $(n=6 ; 9 \%)[13 \cdot$, $15 \bullet, 25 \bullet, 63 \cdot, 68 \cdot, 74 \cdot]$ or DOAC with other anticoagulants $(n=43,65 \%)$, mainly with VKA $[2 \bullet, 16 \bullet, 19 \bullet, 20 \bullet, 22 \bullet, 25 \bullet$, 


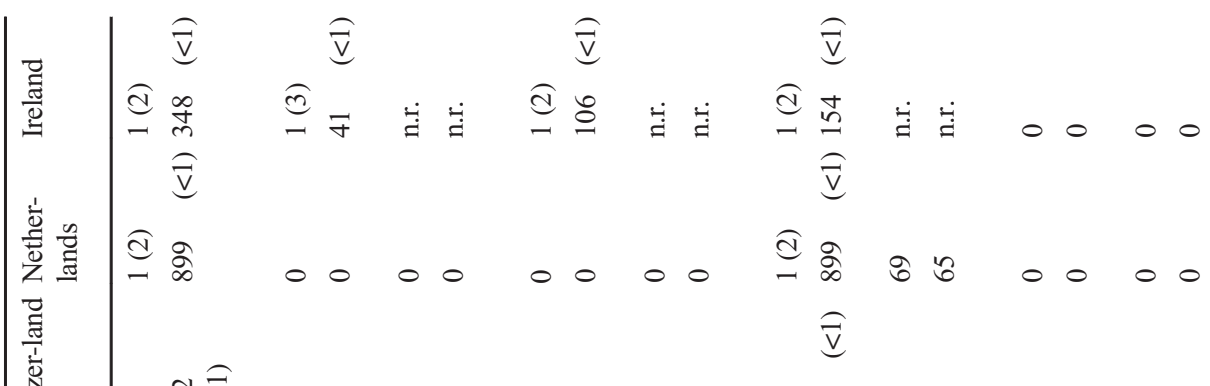

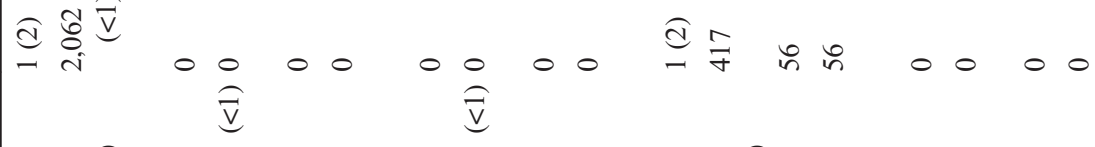

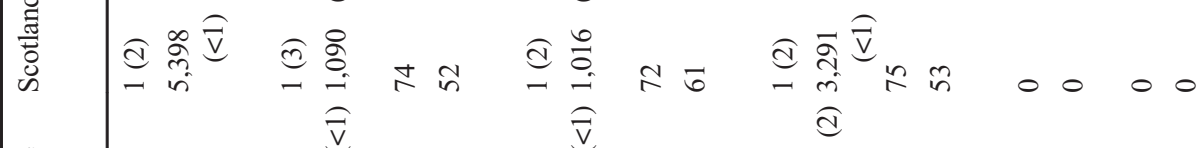

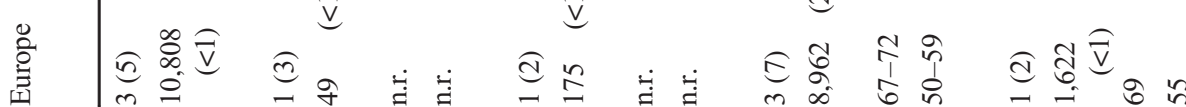
产

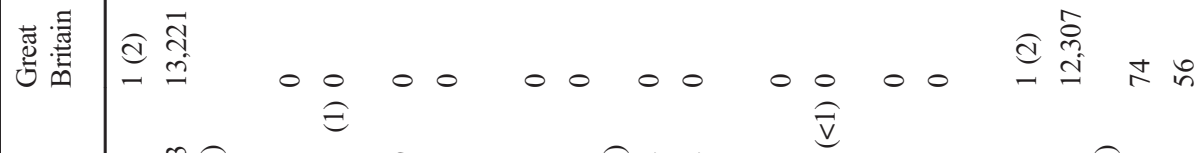

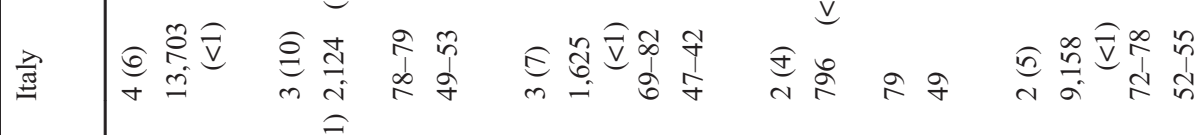

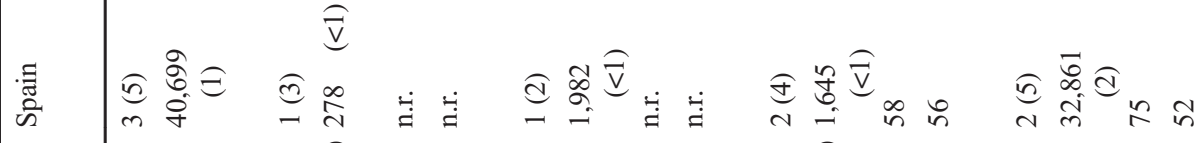

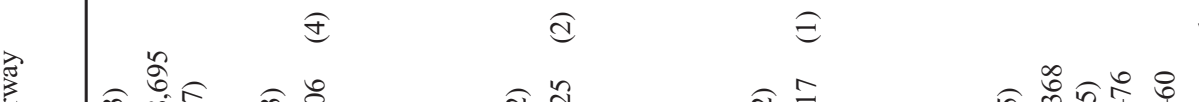

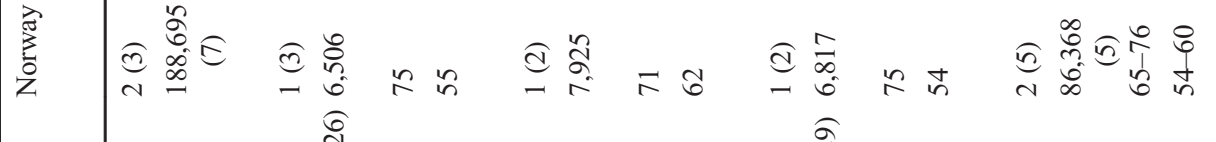

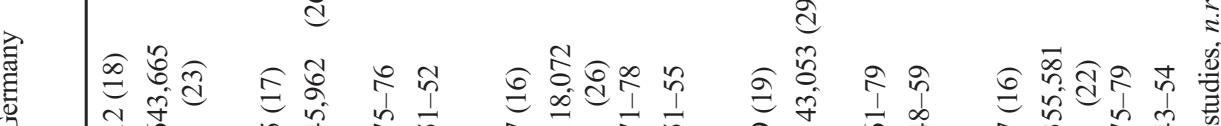

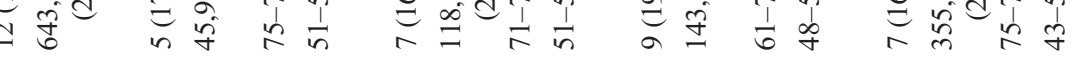

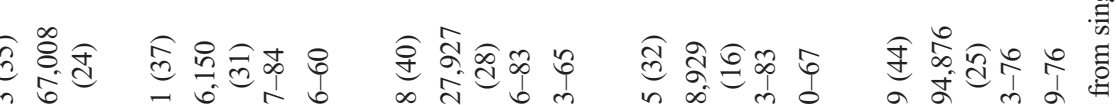

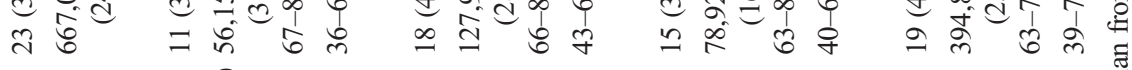

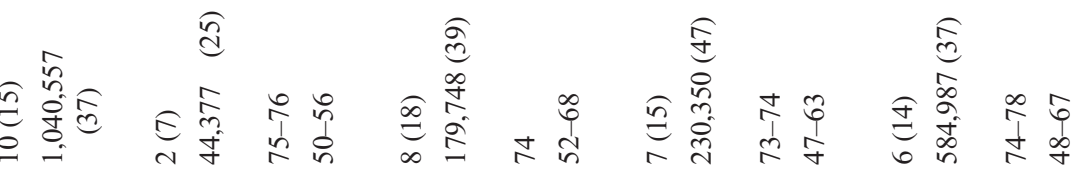

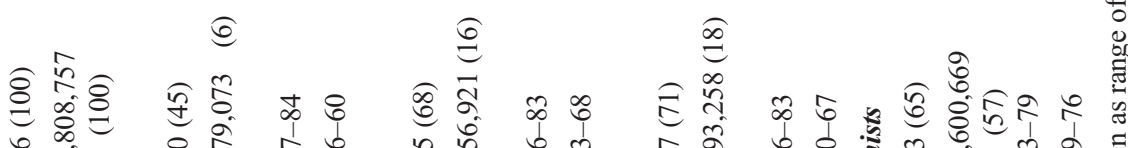

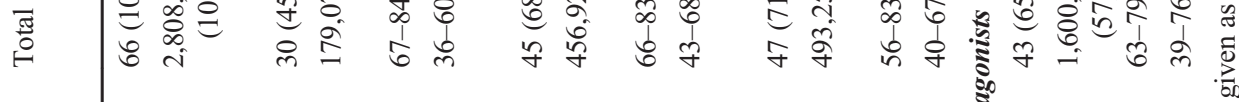

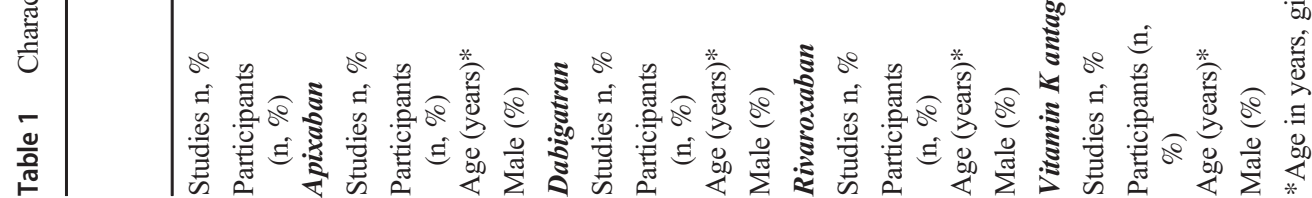




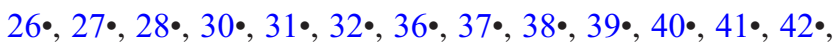

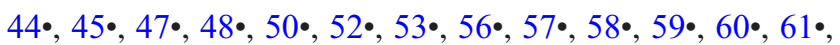
$62 \bullet, 64 \bullet, 65 \bullet, 66 \bullet, 67 \bullet, 69 \bullet, 70 \bullet, 71 \bullet, 72 \bullet, 75 \bullet, 76 \bullet]$.

Some of the studies did not report baseline characteristics stratified by users of single substances and presented only data for users of the drug class. All studies presented data on age, sex and comorbidity with different levels of detail (Appendix Table 4 and Table 5). Information on the HAS-BLED score was provided in 40 studies $(61 \%)$, on the CHA2DS2-VASc score in 48 studies $(73 \%)$ and on the Charlson comorbidity index in nine studies $(14 \%)$. All studies reported information regarding conflicts of interest; eight studies (12\%) reported that there were no conflicts of interest and 42 (64\%) declared their funding.

\section{Characteristics of Patients}

\section{Anticoagulants}

In total, 1,600,669 patients $(57 \%)$ were treated with VKA, $1,205,908(43 \%)$ with DOAC and $2071(<1 \%)$ with other anticoagulants (e.g. heparins). Among patients treated with DOAC, 493,258 (41\%) used rivaroxaban; 456,921 (38\%), dabigatran; and 179,073 (15\%), apixaban (Table 1). There was no study describing patients treated with edoxaban.

In the Danish studies, dabigatran was the most often used DOAC (31-78\%), except for the prophylaxis of venous thromboembolism where rivaroxaban had the greatest share $(80 \%)$. In the German studies, the Irish study and the Scottish study, rivaroxaban was the most often prescribed DOAC (59$67 \%, 44 \%$ and $61 \%$, respectively). In France and Spain, dabigatran and rivaroxaban were prescribed with the same frequency. In Italy and Sweden, apixaban, dabigatran and rivaroxaban were used with the same frequency (Appendix Table 4 and Table 5).

\section{Age}

Overall, patients treated with DOAC had a higher mean or median age, and their age range was wider compared with patients receiving VKA (mean age 56-84 years vs. 6379 years). Of the 43 studies comparing DOAC users with VKA users, 15 studies (35\%) reported no age differences between the two groups (Appendix Table 4 and Table 5). Fourteen studies $(33 \%)$ reported a higher age of patients receiving DOAC compared with those treated with VKA $[2 \cdot$, $22 \bullet, 26 \bullet, 27 \bullet, 36 \bullet, 44 \bullet, 45 \bullet, 50 \bullet, 52 \bullet, 57 \bullet, 62 \bullet, 69 \bullet, 75 \bullet, 76 \bullet]$; the mean age varied by about 1 year in most of these studies. Seven studies (16\%) reported that patients using DOAC were younger compared with those receiving VKA $[20 \bullet, 47 \bullet, 58 \bullet$, $59 \bullet, 60 \bullet, 65 \bullet, 72 \bullet]$, and seven studies $(16 \%)$ reported age differences related to the received doses of DOAC and VKA $[16 \bullet, 37 \bullet, 39 \bullet, 40 \bullet, 41 \bullet, 67 \bullet, 70 \bullet]$.
Eleven studies reported a higher age for patients treated with apixaban and rivaroxaban compared with patients using dabigatran $[12 \bullet, 22 \bullet, 27 \bullet, 28 \bullet, 36 \bullet, 42 \bullet, 51 \bullet, 64 \bullet, 66 \bullet, 69 \bullet$, $7^{\circ}$ ], and four studies described a higher age for patients with apixaban compared with the other DOAC $[30 \bullet, 31 \bullet, 32 \bullet, 52 \bullet]$. Among DOAC, rivaroxaban was prescribed in the widest age range (mean age 56-83 years vs. 65-84 years). Patients treated with lower doses were older than patients receiving the respective standard dose $[13 \bullet, 15 \bullet, 16 \bullet, 24 \bullet, 25 \bullet, 37 \bullet, 39 \bullet$, $40 \bullet, 41 \bullet, 67 \bullet, 68 \bullet, 70 \bullet, 74 \bullet]$.

In Italy, patients using apixaban were older than those in the other European countries (78-79 years vs. 74-76 years). In Denmark, the range of mean or median age was wider for patients with apixaban (67-84 years) and dabigatran (6683 years) compared with patients with rivaroxaban and VKA. This was also the case for dabigatran in Italy (6982 years) compared with apixaban, rivaroxaban and VKA. Patients treated with rivaroxaban were older in the Danish, Italian and German studies compared with the patients in the studies from the other countries (63-83, 79 and 61-79 years, respectively, vs. 56-75 years). In the Danish and Norwegian studies, VKA were prescribed in a wider mean age range compared with the other European countries (63-76 as well as $65-76$ years vs. $74-79$ years).

\section{Sex}

There were no differences regarding the distribution of sex in 32 studies (48\%) (Appendix Table 4 and Table 5). In six studies (10\%), a higher proportion of women was observed in patients with reduced doses of dabigatran and rivaroxaban compared those with the standard dose. The studies on DOAC reported a proportion of male patients of 36-68\% (Table 1). For apixaban, a proportion of male patients of $49-55 \%$ was reported, except for the Danish studies where the proportion varied between 36 and $60 \%$. For dabigatran, $43-68 \%$ of male patients were reported, and for rivaroxaban, 40-67\%. For VKA, the proportion of male patients was $43-57 \%$, except for Danish studies where the proportion varied between 39 and $76 \%$.

\section{Comorbidity}

Ten of the 66 studies did not report on the prevalence of comorbidities stratified by users of different substances, and four studies provided no information on specific comorbidities. Among the 43 studies comparing DOAC with VKA, $32 \%(n=14)$ reported more strokes at the baseline in users of DOAC compared with users of VKA $[2 \bullet, 19 \bullet, 25 \bullet, 26 \bullet, 27 \bullet$, $30 \bullet, 31 \bullet, 36 \bullet, 40 \bullet, 42 \bullet, 45 \bullet, 52 \bullet, 69 \bullet, 70^{\bullet}$ and in $7 \%$ of the studies $(n=3)$ it was the other way around $[47 \bullet, 61 \bullet, 65 \cdot$. In $21 \%$ of the studies $(n=9)$, the users of DOAC had more prior bleeding compared with VKA users [2•, 25•, 26•, 40•, 52•, 
$57 \bullet, 65 \bullet, 67 \bullet, 70 \bullet]$, and in one study $(2 \%$ of the studies $(n=$ $1)$ ), it was the other way around [47•]. VKA users more often showed heart failure in $35 \%$ of the studies $(n=15)[16 \bullet, 20 \bullet$, 22•, 35•, 36•, 44•, 47•, 53•, 57•, 58•, 59•, 60•, 65•, 66•, 69•], other cardiovascular diseases in $53 \%$ of the studies $(n=23)$ $[2 \bullet, 16 \bullet, 20 \bullet, 22 \bullet, 27 \bullet, 30 \bullet, 31 \bullet, 32 \bullet, 35 \bullet, 37 \bullet, 44 \bullet, 45 \bullet, 57 \bullet$, $58 \bullet, 59 \bullet, 60 \bullet, 61 \bullet, 62 \bullet, 65 \bullet, 66 \bullet, 67 \bullet, 69 \bullet, 72 \bullet$, renal failure in $37 \%$ of the studies $(n=16)[2 \bullet, 18 \bullet, 22 \bullet, 27 \bullet, 30 \bullet, 31 \bullet, 32 \bullet$, $47 \bullet, 53 \bullet, 57 \bullet, 58 \bullet, 59 \bullet, 61 \bullet, 62 \bullet, 70 \bullet, 75 \bullet$ ], diabetes mellitus in $35 \%$ of the studies $(n=15)[2 \bullet, 20 \bullet, 22 \bullet, 26 \bullet, 35 \bullet, 37 \bullet, 44 \bullet$, $47 \bullet, 58 \bullet, 59 \bullet, 60 \bullet, 65 \bullet, 66 \bullet, 67 \bullet, 70 \bullet]$ and cancer in their history in $7 \%$ of the studies $(n=3)[18 \bullet, 26 \bullet, 35 \bullet$ (Appendix Table 4 and Table 5).

The HAS-BLED score at the baseline was reported in 40 studies (61\%), and the CHA2DS2-VASc score, in 48 studies $(73 \%)$. These studies reported the mean, the median or the proportion of patients with a score higher than a specific value (Appendix Table 4). Overall, the mean or median HAS-BLED or CHA2DS2-VASc scores were similar between the oral anticoagulants (Table 2). The Charlson comorbidity index (CCI) was reported only in a few studies $(n=9 ; 14 \%)$ and varied widely between 0.5 and 5.0.

\section{Discussion}

This rapid review, which included 66 studies from 12 European countries with 2,808,757 patients overall, found marked differences in the characteristics of DOAC vs. VKA users with respect to age and comorbidities. Furthermore, the age structure partly varied between the users of different individual DOAC, which may be associated with further differences in risk factors. Interestingly, the risk scores (HASBLED and CHA2DS2-VASc) were typically similar between groups despite the observed differences in age and comorbidity which questions their value for characterizing and comparing user groups - irrespective of their undeniable clinical usefulness.

There are various potential selection mechanisms that could explain why the treatment decision may entail an imbalance in risk profiles (including age) between users of DOAC and users of VKA. In patients who need to see their physician frequently due to severe comorbidities, regular dosage monitoring required for VKA prescriptions may not be perceived as an additional burden, i.e. prescribing of VKA might be preferred in such patients. By contrast, DOAC prescription might be preferred in patients where regular physician visits impose a burden, e.g. in younger, working patients or in older patients with limited mobility who are otherwise healthy. Our finding that a history of either stroke or bleeding was more often reported for DOAC than for VKA users might also suggest a switch due to a prior treatment's lack of effectiveness or safety, respectively. Given that bleeding is the main adverse event of oral anticoagulants, the treatment decisions may also have been affected by the fact that antidotes were only available for VKAs and have only recently become available for DOACs (for dabigatran in 2015 and for apixaban and rivaroxaban in 2018). This is relevant in patients with a high risk of bleeding including frail patients with an increased risk of bleeding due to falls. These aspects may partly explain the differences in risk profiles between DOAC and VKA users observed in our review and which are also supported by recently published findings of the Global Anticoagulant Registry including 24,137 patients from 35 countries with atrial fibrillation who initiated anticoagulation therapy [77•]. At the same time, these aspects illustrate the challenge of adequately balancing the patient groups in observational studies. The severity of comorbidities as well as frailty may play an important role as confounders, i.e. information which is not available or only with varying degrees of validity in many databases. This means that each study comparing DOAC vs. VKA users must be interpreted very carefully, and the comparison of these studies must consider the availability of confounder information as well as the possibility to control for unmeasured confounding in each study.

For different reasons, the HAS-BLED score and the CHA2DS2-VASc score used for patients with atrial fibrillation appear suboptimal to detect relevant differences in the risk profiles between users of different oral anticoagulants. The HAS-BLED score only considers an age above 65 years and does not take into account, for example, diabetes mellitus or heart failure although these comorbidities are also associated with an increased risk of

Table 2 Summary of risk scores of included studies

\begin{tabular}{lllr}
\hline Anticoagulants & HAS-BLED Score & CHA2DS2-VASc Score & CCI Score \\
\hline Apixaban & $1.5-2.9$ & $2.8-4.3$ & 3.4 \\
Dabigatran & $1.5-3.2$ & $2.1-4.6$ & $2.9-5.0$ \\
Rivaroxaban & $1.5-3.0$ & $2.8-4.5$ & $0.5-3.0$ \\
Vitamin K antagonists & $1.5-3.1$ & $2.2-4.8$ & $0.6-5.0$ \\
\hline
\end{tabular}


bleeding [78•]. Furthermore, the HAS-BLED score typically has been reported in a dichotomous way $(<3$ or $\geq 3$ ). The CHA2DS2-VASc score includes information on heart failure, hypertension, diabetes mellitus, prior stroke or transient ischemic attack, prior vascular diseases and sex and age $(<65$ years, $65-74$ years, $>74$ years) $[79 \bullet \bullet, 80 \bullet$ ]. A CHA2DS2-VASc score of 2 and higher classifies a high risk of stroke. This is likely for the majority of patients using oral anticoagulants, i.e. there is limited differentiation if the score is not reported quantitatively. We did not observe differences in the scores between DOAC and VKA in the studies, but we did see differences with respect to age which might be due to the rough classification of age in these scores. However, it could also be that one group has a higher age but lower prevalence of comorbidities, while the opposite is true for the other group, resulting in a similar score in both groups. These aspects point to the importance of reporting the prevalence of relevant comorbidities for different patient groups in studies, in addition to scores which ideally should be reported quantitatively rather than dichotomously.

When comparing the studies conducted in different countries, we observed some differences in the distribution of age. For example, patients treated with rivaroxaban tended to be older in studies conducted in Denmark, Italy and Germany compared with the studies from the other European countries. We also observed marked differences between countries regarding the share of individual DOAC in all DOAC prescriptions which might be due to differences in marketing strategies, costs or reimbursement. This should also be kept in mind when comparing results between different countries. If, for example, there was a "standard" DOAC A in one country prescribed to the majority of patients, alternative DOAC may only be prescribed to patients with special characteristics in that country. The situation could be entirely different in another country. The selection mechanisms could thus differ between countries and entail inter-country differences in the distribution of risk profiles among users of oral anticoagulants. This is even more relevant given that the databases available in the various countries differ regarding the availability of information on relevant confounders. A recently published study reporting the share of DOAC vs. VKA in various countries also supports a strong variation in prescribing behaviour across countries [77•].

To the best of our knowledge, this is the most comprehensive overview of studies reporting on the risk profiles among users of oral anticoagulants in Europe to date. We used a methodology similar to a systematic review. We searched the two most important electronic databases in the field (MEDLINE and EMBASE) but cannot rule out that relevant articles were missed. It is possible that relevant articles were not found because of the restriction of search terms within the title or because of the language restriction. The screening and extraction processes were conducted by one person, following the method of rapid reviews. The information provided in this review is partly limited due to differences in the methods of the included studies; incompleteness of data, i.e. not all of the studies reported baseline characteristics stratified by single substances; and differences in the level of details in included data. Additionally, another limitation is that studies may have used different approaches to assess differences between groups. We hope that this review stimulates a more comprehensive reporting in future studies that will facilitate the comparison of risk profiles.

In conclusion, our review found relevant differences in the risk profiles of DOAC vs. VKA users and also between users of individual DOAC. Furthermore, our review suggests that the user characteristics may partly differ between countries. This requires careful consideration in the interpretation of observational studies comparing the effectiveness and risks of these drugs.

Acknowledgements The authors would like to thank Lara Christianson, Andreas Schwindt and Dr. Heike Gerds (Leibniz Institute for Prevention Research and Epidemiologie - BIPS, Bremen, Germany) for their support.

Authors' Contributions Katrin Krueger designed and conducted the work, analysed and interpreted the data and drafted the article. Ulrike Haug provided the idea for the research project, interpreted the data and revised the manuscript. Kathrin Jobski interpreted the data and revised the manuscript. Annemarie Voss revised the manuscript. All authors approved the version to be published and agreed to be accountable for all aspects of the work in ensuring that questions related to the accuracy or integrity of any part of the work are appropriately investigated and resolved.

Funding Open Access funding enabled and organized by Projekt DEAL.

\section{Compliance with Ethical Standards}

Conflict of Interest The authors declare that they have no conflict of interest.

Human and Animal Rights and Informed Consent This article does not contain any studies with human or animal subjects performed by any of the authors.

Open Access This article is licensed under a Creative Commons Attribution 4.0 International License, which permits use, sharing, adaptation, distribution and reproduction in any medium or format, as long as you give appropriate credit to the original author(s) and the source, provide a link to the Creative Commons licence, and indicate if changes were made. The images or other third party material in this article are included in the article's Creative Commons licence, unless indicated otherwise in a credit line to the material. If material is not included in the article's Creative Commons licence and your intended use is not permitted by statutory regulation or exceeds the permitted use, you will need to obtain permission directly from the copyright holder. To view a copy of this licence, visit http://creativecommons.org/licenses/by/4.0/. 


\section{References}

Papers of particular interest, published recently, have been highlighted as:

- Of importance

- Of major importance

1.• Ibanez L, Sabate M, Vidal X, et al. Incidence of direct oral anticoagulant use in patients with nonvalvular atrial fibrillation and characteristics of users in 6 European countries (2008-2015): A crossnational drug utilization study. Br J Clin Pharmacol. 2019;85: 2524-39 Epidemiological information on incidence of DOAC use in 6 European countries.

2. Ujeyl M, Koster I, Wille H, et al. Comparative risks of bleeding, ischemic stroke and mortality with direct oral anticoagulants versus phenprocoumon in patients with atrial fibrillation. Eur J Clin Pharmacol. 2018;74:1317-25.

3. Kelly SE, Moher D, Clifford TJ. Defining rapid reviews: a modified Delphi consensus approach. Int J Technol Assess Health Care. 2016;32:265-75.

4. Khangura S, Konnyu K, Cushman R, Grimshaw J, Moher D. Evidence summaries: the evolution of a rapid review approach. Syst Rev. 2012;1:10.

5. Tricco AC, Zarin W, Antony J, Hutton B, Moher D, Sherifali D, et al. An international survey and modified Delphi approach revealed numerous rapid review methods. J Clin Epidemiol. 2016;70:61-7.

6. Li Y, Yu J, Du L, et al. Exploration and practice of methods and processes of evidence-based rapid review on peer review of WHO EML application. J Evid Based Med. 2015;8:222-8.

7. Higgins JPT, Green S (editors). Cochrane handbook for systematic reviews of interventions version 5.1.0 [updated March 2011]. The Cochrane Collaboration, 2011. Available from www.handbook. cochrane.org Accessed 11 Nov 2018.

8. Moher D, Liberati A, Tetzlaff J, Altman DG, for the PRISMA Group. Preferred reporting items for systematic reviews and metaanalyses: the PRISMA statement. BMJ. 2009;339:b2535.

9. Liberati A, Altman DG, Tetzlaff J, Mulrow C, Gotzsche PC, Ioannidis JPA, et al. The PRISMA statement for reporting systematic reviews and meta-analyses of studies that evaluate healthcare interventions: explanation and elaboration. BMJ. 2009;339:b2700.

10. The University of Texas - Health Science Centre at Houston. Search Filters for Various Databases. http://libguides.sph.uth.tmc.edu/ search_filters/pubmed_filters. Accessed 26 Jan 2019.

11. Mateen FJ, Oh J, Tergas AI, Bhayani NH, Kamdar BB. Titles versus titles and abstracts for initial screening of articles for systematic reviews. Clin Epidemiol. 2013;5:89-95.

12. Andersson NW, Svanstrom H, Lund M, et al. Comparative effectiveness and safety of apixaban, dabigatran, and rivaroxaban in patients with non-valvular atrial fibrillation. Int J Cardiol. 2018;268:113-9.

13. Beyer-Westendorf J, Ebertz F, Forster K, et al. Effectiveness and safety of dabigatran therapy in daily-care patients with atrial fibrillation. Results from the Dresden NOAC registry. Thromb Haemost. 2015;113:1247-57.

14. Beyer-Westendorf J, Forster K, Ebertz F, Gelbricht V, Schreier T, Gobelt M, et al. Drug persistence with rivaroxaban therapy in atrial fibrillation patients-results from the Dresden non-interventional oral anticoagulation registry. Europace. 2015;17:530-8.

15. Blin P, Dureau-Pournin C, Cottin Y, et al. Comparative effectiveness and safety of standard or reduced dose dabigatran vs. rivaroxaban in nonvalvular atrial fibrillation. Clin Pharmacol Ther. 2018;105(6):1439-55.
16. Blin P, Dureau-Pournin C, Cottin Y, Bénichou J, Mismetti P, Abouelfath A, et al. Effectiveness and safety of 110 or $150 \mathrm{mg}$ dabigatran vs. vitamin $\mathrm{K}$ antagonists in nonvalvular atrial fibrillation. Br J Clin Pharmacol. 2019;85:432-41.

17. Camm AJ, Amarenco P, Haas S, Hess S, Kirchhof P, Kuhls S, et al. XANTUS: a real-world, prospective, observational study of patients treated with rivaroxaban for stroke prevention in atrial fibrillation. Eur Heart J. 2016;37:1145-53.

18. Chopard R, Andarelli JN, Humbert S, Falvo N, Morel-Aleton M, Bonnet B, et al. Prescription patterns of direct oral anticoagulants in pulmonary embolism: a prospective multicenter French registry. Thromb Res. 2019;174:27-33.

19. Collings SL, Lefevre C, Johnson ME, et al. Oral anticoagulant persistence in patients with non-valvular atrial fibrillation: a cohort study using primary care data in Germany. PLoS One. 2017;12: e0185642.

20. Collings SL, Vannier-Moreau V, Johnson ME, Stynes G, Lefèvre $\mathrm{C}$, Maguire A, et al. Initiation and continuation of oral anticoagulant prescriptions for stroke prevention in non-valvular atrial fibrillation: a cohort study in primary care in France. Arch Cardiovasc Dis. 2018;111:370-9.

21. Dallongeville J, Sacher F, Bouee S, et al. Xafran, a drug utilization study of rivaroxaban in stroke prevention in atrial fibrillation in France using a claim database. Therapie. 2018;73:449-60.

22. Friberg L, Oldgren J. Efficacy and safety of non-vitamin K antagonist oral anticoagulants compared with warfarin in patients with atrial fibrillation. Open Heart. 2017;4:e000682.

23. Ghazvinian R, Gottsater A, Elf JL. Efficacy and safety of outpatient treatment with direct oral anticoagulation in pulmonary embolism. J Thromb Thrombolysis. 2018;45:319-24.

24. Gorst-Rasmussen A, Skjoth F, Larsen TB, et al. Dabigatran adherence in atrial fibrillation patients during the first year after diagnosis: a nationwide cohort study. J Thromb Haemost. 2015;13:495504.

25. Gorst-Rasmussen A, Lip GY, Bjerregaard LT. Rivaroxaban versus warfarin and dabigatran in atrial fibrillation: comparative effectiveness and safety in Danish routine care. Pharmacoepidemiol Drug Saf. 2016;25:1236-44.

26. Grove EL, Skjoth F, Nielsen PB, et al. Effectiveness and safety of self-managed oral anticoagulant therapy compared with direct oral anticoagulants in patients with atrial fibrillation. Sci Rep. 2018;8: 15805 .

27. Gundlund A, Staerk L, Fosbol EL, et al. Initiation of anticoagulation in atrial fibrillation: which factors are associated with choice of anticoagulant? J Intern Med. 2017;282:164-74.

28. Halvorsen S, Ghanima W, Fride Tvete I, Hoxmark C, Falck P, Solli $\mathrm{O}$, et al. A nationwide registry study to compare bleeding rates in patients with atrial fibrillation being prescribed oral anticoagulants. Eur Heart J Cardiovasc Pharmacother. 2017;3:28-36.

29. Hecker J, Marten S, Keller L, Helmert S, Michalski F, Werth S, et al. Effectiveness and safety of rivaroxaban therapy in daily-care patients with atrial fibrillation. Results from the Dresden NOAC Registry. Thromb Haemost. 2016;115:939-49.

30. Hohnloser SH, Basic E, Hohmann C, Nabauer M. Effectiveness and safety of non-vitamin $\mathrm{K}$ oral anticoagulants in comparison to phenprocoumon: data from 61,000 patients with atrial fibrillation. Thromb Haemost. 2018;118:526-38.

31. Hohnloser SH, Basic E, Nabauer M. Comparative risk of major bleeding with new oral anticoagulants (NOACs) and phenprocoumon in patients with atrial fibrillation: a postmarketing surveillance study. Clin Res Cardiol. 2017;106:618-28.

32. Huiart L, Ferdynus C, Renoux C, Beaugrand A, Lafarge S, Bruneau $\mathrm{L}$, et al. Trends in initiation of direct oral anticoagulant therapies for atrial fibrillation in a national population-based cross-sectional study in the French health insurance databases. BMJ Open. 2018;8:e18180. 
33. Jara-Palomares L, Sanchez-Oro-Gomez R, Elias-Hernandez T, Morillo-Guerrero R, Ferrer-Galvan M, Asensio-Cruz MI, et al. Rivaroxaban for the treatment of venous thromboembolism. A "real-life" perspective in 103 patients. Thromb Res. 2014;134:617-21.

34. Keller L, Marten S, Hecker J, Sahin K, Tittl L, Beyer-Westendorf J. Venous thromboembolism therapy with rivaroxaban in daily-care patients: results from the Dresden NOAC registry. Int J Cardiol. 2018;257:276-82.

35. Kucher N, Aujesky D, Beer JH, Mazzolai L, Baldi T, Banyai M, et al. Rivaroxaban for the treatment of venous thromboembolism. The SWIss Venous ThromboEmbolism Registry (SWIVTER). Thromb Haemost. 2016;116:472-9.

36. Lamberts M, Staerk L, Olesen JB, Fosbøl EL, Hansen ML, Harboe $\mathrm{L}$, et al. Major bleeding complications and persistence with oral anticoagulation in non-valvular atrial fibrillation: contemporary findings in real-life Danish patients. J Am Heart Assoc. 2017;6(2): 0004517.

37. Larsen TB, Gorst-Rasmussen A, Rasmussen LH, Skjøth F, Rosenzweig M, Lip GYH. Bleeding events among new starters and switchers to dabigatran compared with warfarin in atrial fibrillation. Am J Med. 2014;127:650-6 e655.

38. Larsen TB, Skjoth F, Kjaeldgaard JN, et al. Effectiveness and safety of rivaroxaban and warfarin in patients with unprovoked venous thromboembolism: a propensity-matched nationwide cohort study. Lancet Haematol. 2017;4:e237-44.

39. Larsen TB, Rasmussen LH, Gorst-Rasmussen A, Skjøth F, Lane DA, Lip GYH. Dabigatran and warfarin for secondary prevention of stroke in atrial fibrillation patients: a nationwide cohort study. Am J Med. 2014;127:1172-8 e1175.

40. Larsen TB, Rasmussen LH, Gorst-Rasmussen A, Skjøth F, Rosenzweig M, Lane DA, et al. Myocardial ischemic events in 'real world' patients with atrial fibrillation treated with dabigatran or warfarin. Am J Med. 2014;127:329-36 e324.

41. Larsen TB, Rasmussen LH, Skjoth F, et al. Efficacy and safety of dabigatran etexilate and warfarin in "real-world" patients with atrial fibrillation: a prospective nationwide cohort study. J Am Coll Cardiol. 2013;61:2264-73.

42. Larsen TB, Skjoth F, Nielsen PB, et al. Comparative effectiveness and safety of non-vitamin $\mathrm{K}$ antagonist oral anticoagulants and warfarin in patients with atrial fibrillation: propensity weighted nationwide cohort study. BMJ. 2016;353:i3189.

43. Leschke M, Hess S, Weber E, Haas S. Schlaganfallprävention im Praxisalltag mit Rivaroxaban. Der Klinikarzt. 2017;46:104-10.

44. Lip GYH, Skjoth F, Nielsen PB, et al. Effectiveness and safety of standard-dose nonvitamin $\mathrm{K}$ antagonist oral anticoagulants and warfarin among patients with atrial fibrillation with a single stroke risk factor: a nationwide cohort study. JAMA Cardiol. 2017;2:87281.

45. Martinez CAA, Lanas F, Radaideh G, et al. XANTUS-EL: a realworld, prospective, observational study of patients treated with rivaroxaban for stroke prevention in atrial fibrillation in Eastern Europe, Middle East, Africa and Latin America. Egypt Heart J. 2018;70:307-13.

46. Martinez C, Katholing A, Wallenhorst C, Freedman SB. Therapy persistence in newly diagnosed non-valvular atrial fibrillation treated with warfarin or NOAC. A cohort study. Thromb Haemost. 2016;115:31-9.

47. Maura G, Billionnet C, Alla F, Gagne JJ, Pariente A. Comparison of treatment persistence with dabigatran or rivaroxaban versus vitamin $\mathrm{K}$ antagonist oral anticoagulants in atrial fibrillation patients: a competing risk analysis in the French national health care databases. Pharmacotherapy. 2018;38:6-18.

48. Maura G, Blotiere PO, Bouillon K, et al. Comparison of the shortterm risk of bleeding and arterial thromboembolic events in nonvalvular atrial fibrillation patients newly treated with dabigatran or rivaroxaban versus vitamin $\mathrm{K}$ antagonists: a French nationwide propensity-matched cohort study. Circulation. 2015;132:1252-60.

49. Maura G, Pariente A, Alla F, Billionnet C. Adherence with direct oral anticoagulants in nonvalvular atrial fibrillation new users and associated factors: a French nationwide cohort study. Pharmacoepidemiol Drug Saf. 2017;26:1367-77.

50. Mueller S, Groth A, Spitzer SG, Schramm A, Pfaff A, Maywald U. Real-world effectiveness and safety of oral anticoagulation strategies in atrial fibrillation: a cohort study based on a German claims dataset. Pragmat Obs Res. 2018;9:1-10.

51. Mueller T, Alvarez-Madrazo S, Robertson C, Bennie M. Use of direct oral anticoagulants in patients with atrial fibrillation in Scotland: applying a coherent framework to drug utilisation studies. Pharmacoepidemiol Drug Saf. 2017;26:1378-86.

52. Nielsen PB, Skjoth F, Sogaard M, et al. Effectiveness and safety of reduced dose non-vitamin $\mathrm{K}$ antagonist oral anticoagulants and warfarin in patients with atrial fibrillation: propensity weighted nationwide cohort study. BMJ. 2017;356:j510.

53. Ording AG, Horvath-Puho E, Adelborg K, et al. Thromboembolic and bleeding complications during oral anticoagulation therapy in cancer patients with atrial fibrillation: a Danish nationwide population-based cohort study. Cancer Med. 2017;6:1165-72.

54. Pharithi RB, Ranganathan D, O’Brien J, Egom EE, Burke C, Ryan $\mathrm{D}$, et al. Is the prescription right? A review of non-vitamin $\mathrm{K}$ antagonist anticoagulant (NOAC) prescriptions in patients with nonvalvular atrial fibrillation. Safe prescribing in atrial fibrillation and evaluation of non-vitamin $\mathrm{K}$ oral anticoagulants in stroke prevention (SAFE-NOACS) group. Ir J Med Sci. 2019;188:101-8.

55. Pisters R, van Vugt SPG, Brouwer MA, Elvan A, ten Holt WL, Zwart PAG, et al. Real-life use of rivaroxaban in the Netherlands: data from the Xarelto for Prevention of Stroke in Patients with Atrial Fibrillation (XANTUS) registry. Neth Hear J. 2017;25: 551-8.

56. Potpara TS, Trendafilova E, Dan GA, et al. The patterns of nonvitamin $\mathrm{K}$ antagonist oral anticoagulants (NOACs) use in patients with atrial fibrillation in seven Balkan countries: a report from the BALKAN-AF survey. Adv Ther. 2017;34:2043-57.

57. Ramagopalan S, Allan V, Saragoni S, Esposti LD, Alessandrini D, Perrone V, et al. Patient characteristics and bleeding events in nonvalvular atrial fibrillation patients treated with apixaban or vitamin K antagonists: real-world evidence from Italian administrative databases. J Comp Eff Res. 2018;7:1063-71.

58. Rodriguez-Bernal CL, Hurtado I, Garcia-Sempere A, et al. Oral anticoagulants initiation in patients with atrial fibrillation: realworld data from a population-based cohort. Front Pharmacol. 2017;8:63.

59. Rodriguez-Bernal CL, Peiro S, Hurtado I, et al. Primary nonadherence to oral anticoagulants in patients with atrial fibrillation: real-world data from a population-based cohort. J Manag Care Spec Pharm. 2018;24:440-8.

60. Saliba L, Mondoly P, Duparc A, et al. Factors associated with direct oral anticoagulants versus vitamin $\mathrm{K}$ antagonists in patients with non-valvular atrial fibrillation. Therapie. 2015;70:485-92.

61. Sindet-Pedersen C, Langtved Pallisgaard J, Staerk L, et al. Comparative safety and effectiveness of rivaroxaban versus VKAs in patients with venous thromboembolism. A Danish nationwide registry-based study. Thromb Haemost. 2017;117: 1182-91.

62. Sindet-Pedersen C, Pallisgaard JL, Staerk L, Berger JS, Lamberts $\mathrm{M}$, Torp-Pedersen C, et al. Temporal trends in initiation of VKA, rivaroxaban, apixaban and dabigatran for the treatment of venous thromboembolism - a Danish nationwide cohort study. Sci Rep. 2017;7:3347.

63. Sindet-Pedersen C, Staerk L, Pallisgaard JL, Gerds TA, Berger JS, Torp-Pedersen C, et al. Safety and effectiveness of rivaroxaban and 
apixaban in patients with venous thromboembolism: a nationwide study. Eur Heart J Cardiovasc Pharmacother. 2018;4:220-7.

64. Sjalander S, Sjogren V, Renlund H, et al. Dabigatran, rivaroxaban and apixaban vs. high TTR warfarin in atrial fibrillation. Thromb Res. 2018;167:113-8.

65. Sjogren V, Bystrom B, Renlund H, et al. Non-vitamin K oral anticoagulants are non-inferior for stroke prevention but cause fewer major bleedings than well-managed warfarin: a retrospective register study. PLoS One. 2017;12:e181000.

66. Sogaard M, Nielsen PB, Skjoth F, et al. Rivaroxaban versus warfarin and risk of post-thrombotic syndrome among patients with venous thromboembolism. Am J Med. 2018;131:787-94 e784.

67. Sorensen R, Gislason G, Torp-Pedersen C, et al. Dabigatran use in Danish atrial fibrillation patients in 2011: a nationwide study. BMJ Open. 2013;3:e002758.

68. Staerk L, Gerds TA, Lip GYH, Ozenne B, Bonde AN, Lamberts M, et al. Standard and reduced doses of dabigatran, rivaroxaban and apixaban for stroke prevention in atrial fibrillation: a nationwide cohort study. J Intern Med. 2018;283:45-55.

69. Staerk L, Fosbol EL, Lip GYH, et al. Ischaemic and haemorrhagic stroke associated with non-vitamin $\mathrm{K}$ antagonist oral anticoagulants and warfarin use in patients with atrial fibrillation: a nationwide cohort study. Eur Heart J. 2017;38:907-15.

70. Staerk L, Gislason GH, Lip GY, et al. Risk of gastrointestinal adverse effects of dabigatran compared with warfarin among patients with atrial fibrillation: a nationwide cohort study. Europace. 2015; 17:1215-22.

71. Tanislav C, Allendorfer J, Pfeilschifter W, et al. One decade of oral anticoagulation in stroke patients: results from a large country-wide hospital-based registry. Int J Stroke. 2018;13:308-12.

72. Urbaniak AM, Strom BO, Krontveit R, Svanqvist KH. Prescription patterns of non-vitamin $\mathrm{K}$ oral anticoagulants across indications and factors associated with their increased prescribing in atrial fibrillation between 2012-2015: a study from the Norwegian prescription database. Drugs Aging. 2017;34:635-45.

73. Vedovati MC, Verdecchia P, Giustozzi M, Molini G, Conti S, Pierpaoli L, et al. Permanent discontinuation of non vitamin K oral anticoagulants in real life patients with non-valvular atrial fibrillation. Int J Cardiol. 2017;236:363-9.
74. Verdecchia P, Vedovati MC, Conti S, Giustozzi M, Aita A, Molini $\mathrm{G}$, et al. Long-term outcome in patients with non-valvular atrial fibrillation on dabigatran: a prospective cohort study. Expert Opin Drug Saf. 2018;17:1063-9.

75. Volterrani M, Iellamo F, Alberto C, et al. NOAC in "real world" patients with atrial fibrillation in Italy: results from the ISPAF-2 (Indagine Sicoa Paziente Con Fibrillazione Atriale) survey study. Intern Emerg Med. 2018;13:1069-75.

76. Wilke T, Groth A, Pfannkuche M, Harks O, Fuchs A, Maywald U, et al. Real life anticoagulation treatment of patients with atrial fibrillation in Germany: extent and causes of anticoagulant underuse. J Thromb Thrombolysis. 2015;40:97-107.

77. Haas S, Camm AJ, Bassand JP, Angchaisuksiri P, Cools F, Corbalan R, et al. Predictors of NOAC versus VKA use for stroke prevention in patients with newly diagnosed atrial fibrillation: results from GARFIELD-AF. Am Heart J. 2019;213:35-46.

78.• Lip GY, Frison L, Halperin JL, Lane DA. Comparative validation of a novel risk score for predicting bleeding risk in anticoagulated patients with atrial fibrillation: the HAS-BLED (Hypertension, Abnormal Renal/Liver Function, Stroke, Bleeding History or Predisposition, Labile INR, Elderly, Drugs/Alcohol Concomitantly) score. J Am Coll Cardiol. 2011;57:173-80 Validation of the HAS-BLED score for predicting bleeding risk in anticoagulated patients.

79.• Pamukcu B, Lip GY, Lane DA. Simplifying stroke risk stratification in atrial fibrillation patients: implications of the CHA2DS2VASc risk stratification scores. Age Ageing. 2010;39:533-5 Stroke risk stratification with the CHA2DS2-VaSc score.

80.• Lip GY, Nieuwlaat R, Pisters R, et al. Refining clinical risk stratification for predicting stroke and thromboembolism in atrial fibrillation using a novel risk factor-based approach: the Euro Heart Survey on Atrial Fibrillation. Chest. 2010;137:263-72 Clinical risk stratification for predicting stroke and thromboembolism.

Publisher's Note Springer Nature remains neutral with regard to jurisdictional claims in published maps and institutional affiliations. 